\title{
Out of Order: Function and Malfunction in the Biological and Biomedical Sciences
}

\author{
Isabella Sarto-Jackson ${ }^{1}$ (D)
}

Published online: 22 January 2018

(C) Konrad Lorenz Institute for Evolution and Cognition Research 2018

\begin{abstract}
Now take a human body. Why wouldn't you like to see a human body with a curling tail with a crest of ostrich feathers at the end? And with ears shaped like acanthus leaves? It would be ornamental, you know, instead of the stark, bare ugliness we have now. Well, why don't you like the idea? Because it would be useless and pointless. Because the beauty of the human body is that it hasn't a single muscle which doesn't serve its purpose; that there's not a line wasted; that every detail of it fits one idea, the idea of a man and the life of a man.
\end{abstract}

(Rand 1943, p. 405)

Ayn Rand's main protagonist in The Fountainhead, the obstinate architect Howard Roark, compares his view of an architectural masterpiece to the impeccable organization of the human body. According to Roark, every inch of the human body serves a purpose, a conviction he applies just as much to organisms as to his buildings. ${ }^{1}$ This belief in an optimized organismal organization of the human body (and by extrapolation of living beings in general) has not only been a prevailing subject in literature for a long time, but has also reached broad significance in the natural sciences. For centuries, the consensus view of the human body in the biological and biomedical sciences was epitomized in the notion of the perfect machine (Ochsner 2010). ${ }^{2}$ We owe the machine analogy to Descartes (Lewontin 1996), whose idea about the organism as a machine has exerted its influence for more than three centuries. The view of organismal

Isabella Sarto-Jackson

isabella.sarto-jackson@kli.ac.at

1 Konrad Lorenz Institute for Evolution and Cognition Research, Klosterneuburg, Austria optimization, on the other hand, was imported with the adaptationist program towards the end of the 19th century. The latter bestowed natural selection with a near omnipotence "in forging organic design and fashioning the best among possible worlds" (Gould and Lewontin 1979, p. 584). These models have served their purpose well and led to important theoretical insights, biotechnological progress, and remarkable biomedical advancements. On the other hand, the perfect machine metaphor is uplifting from a purely psychological point of view, because it conveys a picture of an elaborate, fine-tuned system whose parts ensure a sophisticated and immaculate functioning as a whole due to the specificity and selectivity of the parts. This is reassuring, because it gives the impression of having-in principlecontrol about the comprising units as well as their interrelations, interactions, and underlying mechanisms. Yet, at the same time, the perfect machine model has left scholars grappling with the aftermath of its integral assumptions when dealing with system failure of such allegedly optimized and idealized systems.

To investigate malfunction in complex systems, one must agree first on what the system's natural functioning is. For centuries, biologists, physiologists, and medical practitioners have applied the notion of function to almost every type of structure and process that describe biological phenomena, and they implicitly fell back upon the perfect machine metaphor. Since the 1950s, the concept of function, as used by pundits of those disciplines, has

\footnotetext{
${ }^{1}$ Roark clearly does not consider spandrels (or rather pendentives, for that matter (Gould 1997)) as architectural assets.

2 "When we arrive on this earth we are endowed with the most perfect, the most efficient, and the best constructed machine ever devised-our body. A machine beautifully engineered and constructed with the best materials with no planned obsolescence" (Ochsner 2010, p. 44).
} 
come under philosophical scrutiny. Debates about functional ascriptions and functional explanation in the biological and biomedical sciences culminated in the early 1970s when Larry Wright published his work on the etiological account, and Robert Cummins published his work on the causal-role account. Wright's analyses were rooted in a realist concept of function and claimed that " $[\mathrm{t}]$ he function of $X$ is $Z$ means (a) $X$ is there because it does $Z$; (b) $Z$ is a consequence (or result) of $X$ 's being there" (Wright 1973, p. 161). According to Wright, such a definition of function satisfied three requirements: (1) it offered a criterion for distinguishing a function from a mere effect; (2) it applied both to biology and to artifacts; (3) it was able to capture the normativity of functional ascriptions, that is, the implicit assumptions that malfunction is always a possibility (a given object may have a function, and nevertheless be unable to accomplish that function). Against this claim, Cummins formulated a causal-role concept of functions that defines functions as crucially embedded in a system, thereby giving it its explanatory power. According to the causal-role account, ascribing function to a system is "to ascribe a capacity to it which is singled out by its role in an analysis of some capacity of a containing system" (Cummins 1975, p. 765). The latter concept of function also applied to both biological and technical objects, but did not take into account normativity. In addition, Cummins-in open opposition to Wright-insisted that functional ascriptions had nothing to do with the past history of a system, and should be understood exclusively from the viewpoint of the present organization of a system.

These papers unleashed a debate between authors arguing for "backward looking" or "evolutionary" theories of function adhering to the etiological theory, and authors defending "forward looking" or "dispositional" theories of function along the lines of the causal-role theory of function. The former was picked up by Neander (1991) as "selected effects" functions and Millikan (1984) as "teleofunctions" or "proper functions." More recently, criticism of the etiological theory led to a refinement of this account by several authors (e.g., Godfrey-Smith 1993; Kitcher 1993). On the other hand, the causal-role theory of functions increased in sophistication by drawing from particular cases (Amundson and Lauder 1994). In addition, influential papers considered how to bridge the two approaches and subscribed to some sort of pluralism (e.g., Kitcher 1993; Buller 1998). More recently, the organizational approach of function that focuses on the self-maintenance of the system has gained momentum. It emphasizes a causal loop between the contribution of a trait to the maintenance of the system and the production of the trait by the system (Mossio et al. 2009; Mossio and Moreno 2010). Closely related to Cummin's concept, Boorse
(1976) in his seminal paper defined function as the causal contribution of something to a goal in a teleological system and most importantly connected the debate of function with the debate on health and disease. His concept of disease and health is a non-normative concept that defines health as "typical functioning" based on available physiological knowledge and statistical normality (Boorse 1977). In this view, normative issues come into play only for a subclass of human disease, termed "illness," that refers to disease plus subjective and social components (Boorse 1975). Notwithstanding the degree of sophistication reached by philosophical theories of function at the end of the 1990s, issues around functions and malfunctions have not yet been resolved. According to Huneman (2013), the controversy still revolves mainly around two points of discussion: Firstly, do functional explanations inevitably rely on natural selection? And secondly, are functions generally implemented in mechanisms? In addition, when function is connected with the debate about health and disease, theorists argue whether concepts require room for normativity.

In this thematic section, we get past the fictional engineers cited earlier and leave behind their demands for perfection and the blueprints of their architectural marvels. The articles reassess the modern philosophical debate on function in the perspective of malfunction (or dysfunction) and with respect to the use of these concepts in the biological and biomedical sciences. The section's articles are derived from manuscripts presented at the 4th European Advanced Seminars in the Philosophy of the Life Sciences that took place at the Konrad Lorenz Institute for Evolution and Cognition Research (KLI) in Klosterneuburg, Austria, on September 5-9, 2016 (a more detailed report of the event by Thomas Bonnin et al. (2017) is also included in the thematic section). The authors grapple with the consequences of organisms not being perfect but rather evolutionarily tinkered with (with all the caveats entailed) and concede that the functional organization of living systems is quite different from the functional organization of technological artifacts. The former underlies the imperative of the dual causalities (proximate and ultimate) as well as being embedded in a normative society. How much weight is given to each of the two causal accounts and whether normativism comes into play is a matter of the four authors' focus of research.

Lennart Nordenfelt (2017) argues in his article that contemporary philosophy of health and disease has been mainly focused on the purely scientific and biological point. He scrutinizes the relation between the notion of natural function and concepts of health and disease. $\mathrm{He}$ claims that a concept of health and disease essentially requires a normative component, i.e., an evaluation of the general state of a person that goes well beyond objective measurements sensu Boorse. 
In a different vein, Zachery Ardern (2017) assesses an objectivist issue in his article and picks a bone with the adaptationist view of the etiological theory. He claims that the selected effects account (which adheres to the etiological theory) faces a number of difficulties in light of modern genomic research when called on to determine human pathologies. He identifies three major points of criticism of the modern history account that argue against an uncontestable significance of the selected effects theory for human medicine.

In a somewhat more inclusive approach, I (Isabella Sarto-Jackson 2017) map out the shortcomings of the medical model, particularly when it comes to psychopathologies. I present the criticism that the medical model that is currently the prevailing objectivist concept of health and disease largely draws from causal-mechanistic explanations. An update is urgently required that includes historical, dynamic, and system-level aspects. But rather than revamping the model by methodological advancements, it will be necessary to rework its philosophical roots: the erroneous reliance on the biostatistical theory and on the Modern Synthesis as well as the unduly decoupling of proximate and ultimate explanations of function. The latter point is also subject to detailed scrutiny in Étienne Roux's (2018) article that draws strongly from the organizational account (Mossio and Moreno 2010). He argues that for biological systems, proximate, mechanistic explanation of biological processes, albeit necessary, are insufficient to fully explain the existence of biological phenomena. This is due to the findings that biological systems owe their existence to the consequences of both, proximate and ultimate causes. The convergence of both distinct causal regimes defines a system's normality and imposes rules that limit the possible ways these systems can putatively exist. Roux claims that while a biological function is a quality whose values are defined relative to the norms of the system, a dysfunction can be described by a set of values of the same variable that does not match these norms. This can occur when the system is insensitive to ultimate causation and exclusively determined by mechanistic, proximate causation, thereby escaping its own prescriptive norms.

\section{References}

Amundson R, Lauder GV (1994) Function without purpose: the uses of causal role function in evolutionary biology. Biol Philos 9:443-470

Ardern Z (2017) Dysfunction, disease, and the limits of selection. Biol Theory. https://doi.org/10.1007/s13752-017-0288-0

Bonnin T, Hernández-Chávez P, Hladky M, Suárez Pascal CD (2017) Function and malfunction in the biological and biomedical sciences and social sciences. Biol Theory. https://doi.org/10. 1007/s13752-017-0273-7

Boorse C (1975) On the distinction between disease and illness. Philos Public Aff 5:49-68

Boorse C (1976) Wright on functions. Philos Rev 85:70-86

Boorse C (1977) Health as a theoretical concept. Philos Sci 44:542-573

Buller D (1998) Etiological theories of function: a geographical survey. Biol Philos 13:505-527

Cummins R (1975) Functional analysis. J Philos 72:741-765

Godfrey-Smith P (1993) Functions: consensus without unity. Pac Philos Q 74:196-208

Gould SJ (1997) The exaptive excellence of spandrels as a term and prototype. Proc Natl Acad Sci USA 94:10750-10755

Gould SJ, Lewontin RC (1979) The spandrels of San Marco and the Panglossian paradigm: a critique of the adaptationst programme. Proc R Soc London B 205:581-598

Huneman P (2013) Functions: selection and mechanisms. Springer, Dordrecht

Kitcher P (1993) Function and design. Philos Sci 58:168-184

Lewontin RC (1996) Biology as engineering. In: Collado-Vides J, Magasanik B, Smith TF (eds) Integrative approaches to molecular biology. MIT Press, Cambridge, pp 1-10

Millikan R (1984) Language, thought, and other biological categories: new foundations for realism. MIT Press, Cambridge

Mossio M, Moreno A (2010) Organisational closure in biological organisms. Hist Philos Life Sci 32:269-288

Mossio M, Saborido C, Moreno A (2009) An organizational account of biological functions. Brit J Phil Sci 60:813-841

Neander K (1991) Functions as selected effects: the conceptual analysts defense. Philos Sci 58:168-184

Nordenfelt L (2017) Functions and health: towards a praxis-oriented concept of health. Biol Theory. https://doi.org/10.1007/s13752017-0270-x

Ochsner A (2010) Thoughts on the human body. Ochsner J 10:44-47

Rand A (1943) The fountainhead. The Bobbs-Merrill Company, New York

Roux E (2018) Function, dysfunction, and normality in biological sciences. Biol Theory. https://doi.org/10.1007/s13752-017-0291-5

Sarto-Jackson I (2017) Time for a change: topical amendments to the medical model of disease. Biol Theory. https://doi.org/10.1007/ s13752-017-0289-z

Wright L (1973) Functions. Philos Rev 82:139-168 